Formulation of Position on U.S. Standards Role in Enterprise Integration
Howard M. Bloom

U.S. DEPARTMENT OF COMMERCE Technology Administration National Institute of Standards and Technology

Gaithersburg, MD 20899

August 1994

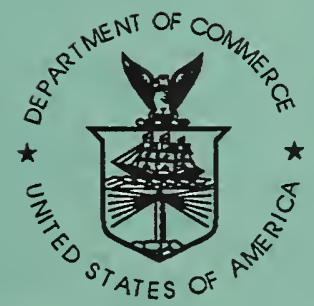

U.S. DEPARTMENT OF COMMERCE Ronald H. Brown, Secretary

TECHNOLOGY ADMINISTRATION Mary L. Good, Under Secretary for Technology NATIONAL INSTITUTE OF STANDARDS AND TECHNOLOGY

Arati Prabhakar, Director
$Q C$

100

.056 N0.5484 

Formulation of Position on U.S. Standards Role in Enterprise Integration

Howard M. Bloom

U.S. DEPARTMENT OF COMMERCE Technology Administration National Institute of Standards and Technology

Gaithersburg, MD 20899 

1. Background $\ldots \ldots \ldots \ldots \ldots \ldots \ldots \ldots \ldots \ldots \ldots \ldots \ldots$

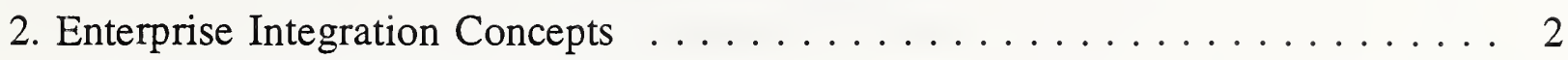

2.1 Classfication of EIF Standards ................ 3

2.2 Strategy for EIF Standards Development ............ 5

3. National Strategy for Enterprise Integration $\ldots \ldots \ldots \ldots \ldots \ldots$

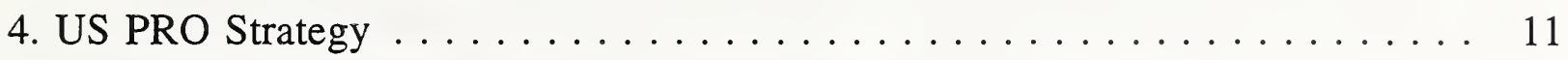

5. Business Case For US PRO Involvement in Enterprise Integration . . . . . . 13

6. Acknowledgements . . . . . . . . . . . . . . . . . 15

7. References .............................. 16

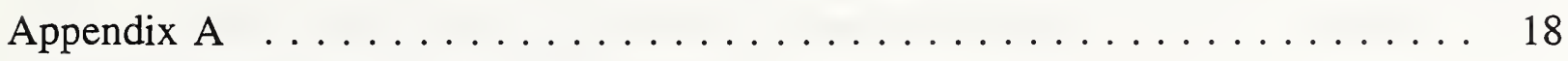

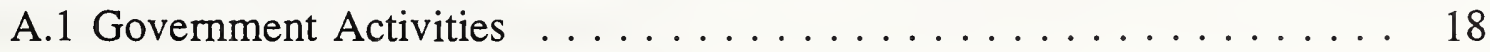

A.1.1 Interagency Activities $\ldots \ldots \ldots \ldots \ldots \ldots \ldots \ldots \ldots$

A.1.2 Agency Activities .................. 19

A.2 Joint Industry/Government Activities . . . . . . . . . . . 23

A.3 Industrial Consortia Activities . . . . . . . . . . . . 23

Appendix B . . . . . . . . . . . . . . . . . . . . 30

B.1 Major Standards for Enterprise Integration $\ldots \ldots \ldots \ldots \ldots \ldots$

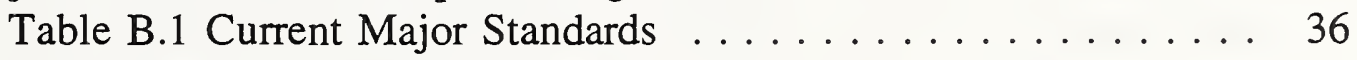

Table B.2 Major Standards 2-7 Years . . . . . . . . . . . . 37

Table B.3 Major Standards 8 Years and Beyond . . . . . . . . 37

B.2 Major Standards for CALS . . . . . . . . . . . . . 37

Table B.3 List of Major CALS Standards . . . . . . . . . 38 



\title{
FORMULATION OF POSITION \\ ON US STANDARDS ROLE IN ENTERPRISE INTEGRATION
}

\author{
Howard M. Bloom
}

August 16, 1994

\section{BACKGROUND}

The National Institute of Standards and Technology (NIST) has been a key player in the development of product data exchange standards. In fact, NIST has been the chair, since its conception, of the IGES/PDES Organization (IPO) which is the official ANSI standards body for product data exchange standards. In addition, NIST has been both the chair and secretariat, since its conception, of the international standards committee that creates product data exchange standards. This paper presents a NIST position on the importance of the US standards community to take a more active role in the development of standards relating to EI. The paper is addressed to the US PRO which is the parent organization of the IPO, as a means of opening discussion on an extension of the scope of the standards work that the organization oversees in support of the US efforts in data exchange standards into EI development.

The US PRO has defined a scope for its standards activity that involves the development of product data exchange standards such as the Initial Graphics Exchange Specification (IGES) and the Standard for the Exchange of Product Model Data (STEP) (through its Product Data Exchange using STEP (PDES) project). However, there are other standards activities that involve the development of data exchange standards that could critically influence the impact of STEP on the industrial community. At the top of these standards is the concept of an "Enterprise Integrated Framework (EIF)." Below this level, there are a variety of possible interface standards that include product data exchange, process data exchange (e.g. MANDATE - an ISO standards activity involving manufacturing shop floor data), and electronic data interchange for commerce (e.g. EDI). All of these standards must ultimately be accessible through an enterprise-wide database that is built on a meta-model that defines the syntax and semantic schemas for the information representations required for the functioning of the enterprise. In addition, there is a whole framework of information-technology-related standards (e.g. RDA, SQL, SGML, ODP, POSIX) that must be integrated with the interface standards to represent the total information for a manufacturing enterprise.

At the present time, there is no focused standards effort regarding enterprise integrated frameworks in the U.S. other than the U.S. TAG to TC184/SC5/WG1 (last chaired by IBM and administered by NEMA). Similarly, there have been many technology 
development efforts initiated in the U.S., but there has been no coordinated national effort. However, there is now an effort by government and industry to put together an executive board (a combination of the National Initiative for Product Data Exchange Executive Board and the CALS Executive Council) that would provide a direction for the U.S. in enterprise integration (EI). It is a critical moment for a standards organization to propose coordinating standards and technology development efforts so that EIF standardsconformant systems can be built.

The paper gives a brief overview of the concepts of EI (Section 2), defines a national strategy for EI that involves not only US PRO but also the government and industry groups with an interest in the EI technology and standards (Section 3), and proposes that the US PRO develop a new extended scope for the IPO that will tackle the EI standards issues (Section 4). Finally, a business case for US PRO involvement in EI is discussed (Section 5), first through the identification of key issues requiring resolution, and then through listing the pros and cons of extending the scope to EI framework standards. As reference information to support the white paper, the key government and industrial groups that are involved in EI-related technology development programs are described in Appendix $A$ and the organizations that have a stake in the standards process are described in Appendix B.

\section{ENTERPRISE INTEGRATION CONCEPTS}

The most recent comprehensive discussion of enterprise integration and its associated standards and technology was developed at the International Conference on Enterprise Modeling Technology [ICEI92]. The basic definition of EI as used by this conference is the following:

Enterprise integration (EI) is the task of improving the performance of complex processes by managing the interactions among the participants.

There are several key terms that need to be defined if one is to work in the area of EI (extracted from [EIFG90] and based to a large extent on the CIM-OSA model):

Enterprise - The entire business organization under discussion. It may consist of one or many establishments, divisions, plants, warehouses, or processes within organizations.

Enterprise Activity - Precise definition of the activities of the enterprise in terms of its inputs (required to execute the activity), its outputs (resulting from the execution of the activity) and its function.

Enterprise Framework - An orderly structure which can be used to specify, 
evaluate, implement, and maintain an enterprise's information needs, business process needs, and operational needs.

Enterprise Integration Framework - The structure through which to manage development, design, implementation, and maintenance of an entire enterprise's functional, informational, resource, and organizational needs but with the constraint that integration be applied.

Enterprise Model - Describes what the enterprise does (in terms of processes and functions), what the enterprise uses (in terms of resources and data) and how the enterprise is organized in terms of organization of responsibility i.e. organizational charts and rules). The physical organization of resources (i.e. plant layouts) describes the functional structure of a particular enterprise by providing the "WHAT" and the. "HOW."

Enterprise Object - An information representation of the customer view of the data used in the domain.

Enterprise Views - The decomposition of enterprise knowledge into fundamental areas. It consists of four different views: function, information, resource, and organization. (These views are reflected in the enterprise models.)

In a development plan for the EIF [EIFD89], a set of critical factors for implementing an EIF were listed:

Framework Standards - Covers all EIF modeling definition requirements, as well as definition of the EIF boundary.

EIF Technology - Includes tools and products to facilitate and enable EIF implementation. Repository technology is key to EIF success.

EIF Standards. Specifications, and Requirements Validation - Assures consensus, correctness, completeness and consistency of EIF.

Change Management - Provides support of an EIF implementation.

\subsection{CLASSIFICATION OF EIF STANDARDS}

It is important to be able to classify the types of standards that make up the taxonomy of EIF. The European standards community (CEN/CENELEC) published a report [ITAE90] that has been formally accepted as the European strategy in the area of advanced 
manufacturing technology and which with little exception applies to EIF. The European report developed a classification scheme that identified seven key standards areas in support of Advanced Manufacturing Technology (AMT) applications: interworking, data, processing, control equipment, human aspects, mechanical aspects, and general aspects. (The ANSI CIM Standards Board is also adopting this taxonomy with probably small changes in order to classify all the standards activities under its domain.)

Interworking standards cover the general framework for Computer Integrated Manufacturing, concentrating on Architecture and Intercommunications. (It is actually in this area that most of the proposed work in EIF would be classified.)

The four subcomponents are: Manufacturing Environment Architecture, OSI Standards for Industrial Applications, Standards for Industrial Communications, and Functional Standards for Industrial Communications.

Data standards cover the definition of information and related application data used, stored, and exchanged by applications within an industrial enterprise. Classes of data include administrative, technical and product definition, and manufacturing process. It also implies the use of a general methodology for defining data elements. (For example, STEP falls into this category.)

The four subcomponents are: general method for definition of application data, applications data, standards parts libraries, and group technology.

Processing standards allow industrial users to choose freely both the hardware and software data processing elements best suited to their problem, and to assemble and interconnect these elements. These processes must satisfy such requirements as portability and modularity. It also specifies general programming languages, common operating systems, shared database systems, and software tools and methodologies.

The nine subcomponents are: software portability, software modularity, general programming languages, operating systems, database systems, knowledge based techniques, data security, application languages, and software tools \& methodologies.

Control Equipment standards define interfaces for manufacturing systems, industrial machines, transportation systems, testing devices, process controls and storage systems.

The nine subcomponents are: Numerically Controlled equipment for machines, Coordinate Measurement Machine controllers, robot controllers, 
programmable controllers, process control subsystems, transport system controllers, automatic testing equipment, data entry terminals, and sensors.

Human Aspects standards cover the integration of human operators into an AMT environment.

The two subcomponents are man-machine interface and ergonomics.

Mechanical Aspects standards comprise questions of a mainly physical nature related to machines.

The four subcomponents are: machines, industrial robots, auxiliary equipment, and machine data.

General Aspects standards concern activities or functions which are applicable throughout AMT systems.

The eight subcomponents are: Methodology, Operational Safety, Documentation, Performance Testing, Implementation Guidelines, Operating Environment, Terminology, and Maintenance \& Systems Integrity.

The seven standards areas listed above were intended to represent key topics for AMT. In actuality, they identify the components (with a few additions to allow for generalized enterprises besides manufacturing) of an enterprise integration framework (EIF). The purpose of such a framework is to provide a common basis for identifying and coordinating standards development for the purpose of enterprise modelling and systems integration, while allowing existing standards to be placed into perspective within the framework. In addition, the scope of a virtual enterprise would include items that extend beyond a manufacturing enterprise such as anti-trust, accounting standards, union agents, liability, safety, proprietary data, and harmonization of local regulations.

\subsection{STRATEGY FOR EIF STANDARDS DEVELOPMENT}

It is impossible for any standards organization to manage the total spectrum of standards that fall under the category of EIF (or advanced manufacturing technology). It is the purpose of this paper to identify the complete span of standards, and then to describe how product data exchange (PDE) standards efforts need to be extended to cover high level enterprise framework and modeling efforts. There are whole classes of standards, primarily in the information technology area, that must be integrated with PDE and EIF work but are being (and should continue to be) managed by other standards activities. 
However, any strategy for EIF must include a plan for the entire spectrum of efforts. This will be covered in Section 3 of this paper.

In a July 1994 letter to me, which Greg Winchester of the National Electrical Manufacturers Association (NEMA), secretary to ISO/TC184/SC5 and the administrator of the U.S. TAG to SC5, expressed his views on the emerging draft framework [FEM94] and the SC5/WG1 activity. He stated that the U.S. involvement in WG1 work is very weak, having been on a decline for several years. The portion of the U.S. TAG to SC5 WG1 has not met for over a year. On the international level, Randy Aranguren, the WG1 convenor, was to resign the post at the end of April. If there is no American to replace him, then Greg will have to consult with other countries, particularly France and Germany, the two leading proponents in the CIM-OSA project (see page 9).

Winchester believes that one reason for poor U.S. participation is the fact that the group is developing a general framework standard, as opposed to a specific model incorporating tools and methodologies, as in the European erffort (see Appendix A - AMICE for details). However, the standard will identify the activities within an enterprise to which the tools and methodologies marketed by systems companies can be applied. The bottom-line oriented U.S. company will see benefit in standards involvement when ISO begins addressing some of these tools and methodologies - their saleable products. This is why he believes that STEP has been a much more successful endeavor in the United States.

There are several references to key STEP (SC4) efforts in the framework draft. For example, in the realm of enterprise modeling there are reusable models form the business modeling phase and components such as software modules (for the systems engineering and realization phase) or models to operate the enterprise. In this area specific standardization activities are required (ISO TC184/SC4/WG8(MANDATE) or STEP are examples for this kind of activities).

The overall framework for enterprise modeling refers to Open EDI for business modeling; STEP, EXPRESS (G), and Open EDI for organizational \& technical systems design; and CORBA/OMG and OSF/DCE for the realization. In terms of the enterprise modeling and information technology support, the Application Programming Interface (API) is defined as enabling the writing of distributed applications with non-expert programmers. The API consists of programming language specifications, service specifications, and environment specifications. It is obviously critical for the STEP Standard Data Access Interface (SDAI) to be consistent with the API concept.

In the proposed framework draft, the following key issues are addressed:

The included standards must have a domain of discourse which includes at least 
the following characteristics: business practices, suppliers, processes, customers, enabling resources \& technology, and life cycle.

The included standards must relate to computer employment and/or implementable techniques and methodologies.

The framework will allow for the organization of relevant elements of an enterprise within models that can be used to: (a) expose a partial aspect of the total enterprise operation, (b) aid in the definition of the structure and logic of part of the enterprise, (c) provide an enterprise description needed by people and information technology which control the enterprise, and (d) identify and define enterprise elements provided by standardization of reusable components.

The framework should provide for the coordination of models and modeling languages to harmonize existing, emerging and future standards for enterprise modeling.

In sum, the strategy of this paper is to position the PDE standards activities to extend into the enterprise framework and modeling areas. Without U.S. participation in the national and international EIF activities, we will lose the link to the international work and perhaps leadership in this area. However, in terms of the broad set of information technology (IT) standards that surrounds EIF, the intention is to follow them closely but the coordination should be through other mechanisms than US PRO.

\section{NATIONAL STRATEGY FOR ENTERPRISE INTEGRATION}

A plan needs to be developed that demonstrates how government and industry efforts can be coordinated and integrated into the development of EIF standards. The plan should address activities that fall within the operation of the standards efforts, as well as technology development efforts by industry and government programs that will result in future standards in EIF. The following activities are critical as a strategy for effective U.S. implementation of EIF technology:

* Develop a national consensus on the definition of EIF.

*nitiate U.S. standards efforts in support of the development of standards that fall within the EIF environment.

* Identify and implement tools and products that support the EIF technology.

*Develop the tools and methodologies for testing EIF standards and related applications. 
*nitiate efforts for the development of information systems that utilize the EIF standards and can show support for the enterprise.

\section{National Consensus}

A national consensus on EIF should include the definition of EIF, its components, and applications. The consensus should be accomplished through a series of workshops. The output of the workshops would be a report that includes not only the definition of EIF, but a list of case studies of companies that have used some form of EIF in their business activities. The report should contain requirements for implementing EIF, the tools and technologies needed in an EIF, and identify existing government, industry, and standards related activities in the EIF area.

\section{Standards Body}

Although there is an international standards activity, ISO TC184/SC5/WG1, that is working to define the EIF reference model, there is no corresponding activity in the U.S. that can facilitate the implementation of a national standard. For this reason, the most appropriate U.S. standards body (i.e., the IPO) should propose to the ANSI CIM Standards Board (CIMSB) to create a new standards activity that would have this responsibility. This activity would work closely with the U.S. TAG to SC5/WG1 (the members of the TAG should also be members of this activity) to ensure that the U.S. interests were represented by national consensus.

The standards activity would maintain a database for the standards activities that interface to EIF as part of its responsibility under the CIMSB.

The standards activity would develop a consensus EIF upon which industry application models can be defined. A library of such application models would be maintained by the standards body in much the same manner as a CAD library activity.

\section{Tools and Products}

As the EIF set of standards are being developed, tools such as data modeling packages (e.g. IDEF) will be required. The strategy should be to base these tools on an internationally agreed upon framework. A work item has been submitted to ISO TC184 for a "Framework for CIM Systems Integration." [FCSI90] The scope of this proposed standards activity was "to provide a means of describing enterprises in a computer processable description, to make the computer integration requirements and the forthcoming permanent changes in the discrete parts manufacturing industry manageable." The submitted justification described accurately the state of the advanced manufacturing environment: "Due to fast changes in the market demands, fast changing information 
technology and manufacturing technology, and strong cost competition the manufacturing industry is forced to cope permanently with this environment. Current technology does not offer a solution, how to imbed the islands of automation in an integratable whole." This framework item had such a difficult time in getting consensus among the international members that it has been put aside in favor of less ambitious activities. Recently, another work item "Framework for Enterprise Modeling" [FEM94] has been submitted to TC184/SC5/WG1 tol "provide a framework that coordinates existing, emerging, and future standards for the modeling of manufacturing enterprises to facilitate Computer Integrated Manufacturing."

The Framework effort is based on the ESPRIT Project 688 entitled "Reference Architecture Specification: Proposal for a Framework for CIM System Integration." The name of the framework is CIM-OSA and is being developed by an European consortium, AMICE. The U.S. Government (NIST and DoD) had a memorandum of understanding with AMICE to explore joint development of the tools and methodologies associated with CIM-OSA. The Air Force created a new effort, Enterprise Integration Program (EIP), as a means of working with AMICE to test the relevance of CIM-OSA in meeting the needs of the DoD information systems that support weapons systems development. However, the EIP is no longer being funded. There is a real opportunity to reestablish a formal agreement with ESPRIT to engage in joint research into the supporting technologies [ESPR91].

In order to do joint research, there must be a U.S. sponsored activity in this area. Therefore, it is important to create a coordinated program in the tools and methodologies area. Such a program should be shared by the government and private industry, possibly in the same manner as the CALS - PDES, Inc. partnership, or the ARPA - SEMATECH program.

There are several types of tasks that can be performed:

* Determine the applicability of the CIM-OSA reference model to the needs of U.S. multi-enterprise activities. To accomplish this activity, it will be necessary to "populate" the model with actual information relating to applications from specific industries. The AMICE has been emphasizing shop floor control systems for discrete part manufacturing.

* The CIM-OSA reference model is actually a three dimensional cube that defines (1) levels of genericity (generic, partial, particular), (2) levels of modeling (enterprise, intermediate, implementation), and (3) levels of views (function, information, resource, organization). Projects are needed that can develop a data dictionary that defines all the relevant terminology and their relationships. A language needs to be created that contains the set of primitives needed for using 
the reference model.

* Based on the reference model, a data modeling method must be adopted that allows for the computer interpretable representation of the enterprise. This is a key research and development arena. The U.S. has made a considerable investment in data modeling tools and has used them in modeling manufacturing systems. Further development of such tools to satisfy the extended EIF requirements is needed. A good example was the Air Force ManTech Office's ICAM program.

* Develop a set of application interface specifications for how the present and future enterprise systems (e.g. cost accounting, MRP, design) will work in the EIF.

* Develop an integrated approach to both EIF and STEP frameworks. From a testing viewpoint, the appropriate EIF application specifications can serve as STEP application protocols, and STEP can serve as an information data dictionary to support the EIF.

\section{Testing Methodologies and Tools}

Any standard or framework requires a methodology for performing the validation, verification, and conformance testing as the standards products and technologies come to the market place. A national testbed for EIF testing should be established. The testbed would contain all the information technology systems required for testing the emerging standard and applications that interface to the framework. In addition, the data modeling methodology would be installed at the testbed to be used for populating the EIF. The testbed would serve as the configuration manager for the efforts of other installations involved in the application development for EIF.

\section{Information Systems}

The CIM-OSA document identifies a collection of CIM support systems. There are three categories of systems: basic data processing resources, enterprise engineering functions, and integrated infrastructure. The following descriptions were taken from the CIM-OSA document:

Basic Data Processing Resources are IT services and devices on which the enterprise engineering functions and the integrated infrastructure are implemented. This includes hardware as well as software.

Enterprise Engineering Functions are sets of tools to support the enterprise modelling process. The tools guide the enterprise designer through the steps to 
be performed, offer the constructs and shells for assistance, assist in describing the processes, activities and rules and making use of the shells, identify incompleteness or inconsistencies in the models, offer simulation tools and support the release to operation environment process.

Integrated Infra Structure is a set of IT services which are deemed necessary for the generation and execution of CIM systems complying to the CIM reference model.

The first and third categories basically involve the development of a shared database environment that can support an enterprise. The second category is really the basis for the tools and products defined in the data modeling area referred to in the Tools and Products part of the strategy..

There are many existing projects that could make significant contributions in the IT area as outlined in this stragegy (see Appendix A). It is critical to find a way to coordinate and manage such developments.

\section{US PRO STRATEGY}

Now that the national strategy has been discussed, what specifically should be the role of the US PRO. In order to arrive at a strategy, it is important to summarize the key facts which exist at this time:

*The TC184/SC5/WG1 activity is losing momentum. In addition, the convenor, Randy Aranguren from IBM, announced his resignation. NIST has recently agreed to accept this convenorship and has appointed Jim Nell.

*The CIM-OSA program is entering into its third phase and AMICE is seeking collaboration with the U.S.

*The CIM Standards Board is beginning to develop a taxonomy for coordination of all its standards.

*The NIPDE is entering the last stages of its program. As US PRO considers a transition, it is appropriate to look at the bigger picture beyond just product data standards.

*There is an effort to refocus the NIPDE Executive Board toward a broader standards arena, Enterprise Integration. In this process, there may be a merger of many industry-government boards that will provide guidance in this area. 
*There is at present no national standards body with a scope in EIF. If there is some nationally coordinated technical effort, there needs to be a standards body to perform the formal consensus process.

*STEP is beginning to be implemented in industry. However, for it to succeed it must be integrated into the broader information framework of the companies.

*As EDI continues to progress, it is important to harmonize STEP with it to form the enterprise database.

*There are new National Information Infrastructure activities, both within the government and within industry, e.g. NIIIP, MADE, and SIMA, that are looking at enterprise integration issues.

* There is a new ANSI Technology Reinvestment Program award to develop a database capability for coordinating standards activities.

Now for the recommended strategy:

*The US PRO, through the IPO, applies for extension of its scope to include enterprise integration frameworks.

*The IPO creates a new project, EIF, similar to its three existing projects (e.g. PDES).

*The US PRO works with the emerging National Initiative for Enterprise Integration (if this happens) serving as one of the key standards organizations.

*The US PRO aligns itself through MOUs with key organizations that are engaging in EIF development so that their efforts can proceed through IPO.

*The US PRO participates with the U.S. TAG to TC184/SC5/WG1. If acceptable to NEMA, it should serve as the "informal" administrator for the activities.

*The US PRO will not attempt to coordinate all the IT standards efforts as defined in this white paper. Instead it should propose to have either the ANSI CIM Standards Board, or a group within a new national initiative, do the coordination. 


\section{BUSINESS CASE FOR US PRO INV OLVEMENT IN ENTERPRISE INTEGRATION}

If the strategy of the US PRO extending its scope to include enterprise integration is to be successful, the following issues must be resolved:

* The key standards organizations must approve the US PRO standards plan. The groundwork for this approval has been laid because of the positive responses from CAM-I (the most active standards consortium in EI) and NEMA (the secretariat for SC5/WG1). In addition, approval must be obtained from the ANSI CIM Standards Board, which should not be an issue. (NIST is on the board and is willing to work any problem.) Also, there needs to be a much stronger relationship to the electronic commerce standards activity (working with DISA) so that the two standards (STEP and EDI) are truly harmonized and lead to an integrated enterprise database. Other organizations whose support is important include the ANSI Information Systems Standards Board, CBEMA (administrator of X3) and IEEE (the standards body for IDEF and software engineering tools).

* The newly emerging Enterprise Integration Executive Board must be willing to designate US PRO as a key EI standards body and give encouragement to the US PRO to work with the government and industry programs, in much the same manner that the NIPDE Executive Board does with product data exchange.

* The US PRO must form a collaborative arrangement with the key EI technical programs in much the same manner as it does now with PDES, Inc. and NIDESC in the area of product data exchange. The key programs are being sponsored by ARPA (MADE and NIIIP), CALS, NIST (SIMA and potential ATP awards), DoE (TEAM), CAM-I (CIE and others), MCC (EI Net), NCMS (RRM and others), PDES, Inc., and Sematech (Open CIM Framework). For this collaboration to work effectively, there needs to be an industry/government initiative in EI similar to NIPDE.

* The US PRO needs to obtain an endorsement from key industry bodies such as the CALS Industry Steering Group, the IDEF Users Group and the Agile Manufacturing Enterprise Forum. The CALS Office would be receptive to encouraging these endorsements.

* The US PRO needs to develop a collaborative arrangement with the ESPRIT AMICE consortium, the developers of CIM-OSA. NIST is in a position to facilitate this integration.

* NIST needs to commit to working with the US PRO, other government agencies, and industry programs in the area of EIF in much the same manner as 
it presently does with product data exchange.

If requested, NIST will commit to extending its chairing of the IPO to include the EIF project.

NIST submitted a request for the convenorship of SC5/WG1 and received approval through NEMA.

NIST will seriously consider accepting the role of coordinator for a new initiative in EI, in much the same manner as it presently does for NIPDE.

The SIMA program provides a technology and standards development program that can support the objectives of EIF, in much the same manner as the National PDES Testbed now supports product data exchange.

NIST is positioned as the government coordinator of the Advanced Manufacturing National Challenge under the HPCC/IITA to provide collaboration among the government agency programs in support of the US PRO EIF objectives.

The newly established NIST Office of Enterprise Integration will help to coordinate government policy and procedures in the area of EI as well as provide a communications medium for advancing the concepts of EIF.

The NIST ATP program is actively pursuing the initiation of major programs that will help the development of technology leading to commercialization of EIF-related products.

The NIST MEP program is involved in the development of networks for mid- to small-size companies that can be an invaluable testbed for EI concepts.

There are many good reasons for US PRO to extend its scope to include enterprise integration:

* EIF is a natural extension to the STEP technology. In fact, without close coordination between STEP and EIF, STEP may not be implemented effectively.

* Because an important part of EIF is the enterprise information database, STEP and its shared database implementation should play an important role in specifying EIF standards and the corresponding methodologies and tools. 
* As the work on IGES reaches maintenance level, and the PDES work is done primarily in cooperation with the ISO/STEP activity, it is an opportunity to bring new vigor into IPO.

* It is clear that EIF is becoming more important to industry. US PRO should be able to increase its membership based on this interest.

There are also reasons for US PRO not to extend its scope into enterprise integration:

* Any coordination effort with other data interchange standards bodies, information technology related standards bodies, etc. will greatly increase the level of effort needed by IPO staff.

* If there is no increase in membership, then the IPO may be promising standards it can not produce.

* Without a clear resolution of the issues raised in the US PRO Strategy section, the efforts to develop EIF will not be successful.

* The IPO does not have an existing track record in the area of EI.

This position paper has been presented to both the Steering Committee for the IGES/PDES Organization and the US PRO Board of Directors. At the present time both groups are considering the strategy in terms of the business case that has been described in the paper. I believe that the pros offer an exciting future for the US PRO and for meeting the needs of U.S. manufacturing enterprises. I also believe that there are steps that can be taken to minimize the risks as defined by the cons.

\section{ACKNOWLEDGEMENTS}

I want to thank Mary Mitchell and Jim Nell for their comments in reviewing this document. I also want to thank Randy Aranguren (Convener of SC5/WG1) for his many inputs into the state of EI in the U.S., Bob Boykin (CAM-I) for his input and support, Greg Winchester (NEMA) for his comments on SC5/WG1, Rita Hillyer (CALS) for her input and use of the CALS white paper on EI, and Dave Jefferson (NIST) for the numerous documents on EI-related issues.

\section{REFERENCES}

[AMEF93] Prepared by the Enterprise Integration Focus Group (EIFG) of the Agile Manufacturing Enterprise Forum, "21st Century Manufacturing Enterprise Strategy - Integrating the Agile Virtual Enterprise (Key Need Areas)", 
Volume 3, December 14, 1993.

[CATM94] Committee on Applications and Technology, "Manufacturing and the NII: White Paper," March 1994 (not for distribution)

[DAC190] D. Appleton Company, Inc. "Comparison of Other Integration Programs and Projects to the Enterprise Integration Framework (EIF), 1D-MDR-843030-103, March 15, 1990. (presented to DoD sponsor for the EIF project)

[DAC290] D. Appleton Company, Inc., " Comparison of Enterprise Integration Framework Characteristics Versus Those of Other Known Integration Programs, 1C-EJG-843-030-001, March 26, 1990. (presented to DoD sponsor for the EIF project)

[DIIS93] Proceedings of the JSPE-IFIP WG 5.3 Working Conference on the Design Information Infrastructure Systems for Manufacturing," Tokyo, Japan, November 8-10, 1993, to be published by Elsevier in 1994.

[EIF90] Northrop, "Enterprise Integration Framework - Framework Development,", Contract No. 45324-61089, January, 1990 (presented to DoD sponsor for the EIF project)

[EIFD89] IBM, "Enterprise Integration Framework Development Plan", Document Number EIF-M89-11, January 12, 1990. (presented to DoD sponsor for the EIF project)

[EIFG90] International Business Machines, "Enterprise Integration Framework EIF Glossary," (EIF-M89-14), January 13, 1990.

[ESPR91] "Report of the Workshop on ESPRIT/NIST Collaborative Action for Manufacturing Technologies", held in Berlin, 29 July to 2 August 1991 (available through NIST).

[FCSI90] ISO TC184/SC5/WG1, "Framework for CIM Systems Integration," Document N144, 1990 (available from NEMA).

[FEM93] ISO TC184/SC5/WG1, "Framework for Enterprise Modeling, Document N315, February 1994 (available from NEMA).

[ICEI92] Edited by Charles J. Petrie, Jr., "Enterprise Integration Modeling", Proceedings of the International Conference on Enterprise Integration Modeling Technology (ICEIMT), organized by the US and EC agencies, 
MIT Press, 1992.

[IDA91] "Baseline Report on the Current State of U.S. Enterprise Integration Initiatives," written by IDA, 23 Aug 1991, (Not for Distribution).

[IFAC93 W Williams, T.J. and Bernus, P. and Brosvic, J. and Cheng, D. and Doumeingts, G. and Nemes, L. and Nevins, J.L. and Vallespir, B. and Vlietstra, J., and Zoetekouw, D., " Architectures for Integrating Manufacturing Activities and Enterprises", published in proceedings of IFAC World Congress 1993, Sydney, Vol. X., pp273-283, July, 1993.

[IITA94] "Information Infrastructure Technology and Applications," A report to the HPCCIT, published by the IITA Task Group, January 4, 1994.

[IJCI90] Edited by K. Kosanke, "CIM-OSA Parts 1, 2, and 3", International Journal of Computer Integrated Manufacturing, published by Taylor \& Francis, Volume 3, Numbers 3 and 4, May - August, 1990.

[ITAE90] ITAEGM, "Memorandum M-IT-04 on Directory of European Standardization Requirements for Advanced Manufacturing Technology and Programme for the Development of Standards", prepared by the Information Technology Advisory Expert Group on Advanced Manufacturing Technologies (ITAEGM) under control of the CEN (European Committee for Standardization) / CENELEC (European Committee for Electrotechnical Standardization) / ETSI (European Telecommunications Standards Institute) -- ITSTC (Information Technology Steering Committee), January, 1990.

[MSSP92] "Manufacturing Systems Strategic Plan: Report of the Manufacturing Systems Committee of the Manufacturing Technology Advisory Group," published November, 1992.

[NII93] "The National Information Infrastructure: Agenda for Action," published by the Information Infrastructure Task Group, September 15, 1993.

[TAG89] U.S. Tag to ISO TC 184, "U.S. TAG to ISO TC 184 Program of Work Working Draft 1.0 - N 244", available from NEMA - Tag Administrator, August, 1989. 


\section{APPENDIX A}

\section{TECHNOLOGY DEVELOPMENT PROGRAMS}

This section identifies the key technical programs that have been initiated either by the government or by industrial consortia. (Individual companies have not been listed, although there are many like General Motors who through its $\mathrm{C}^{4}$ program has taken an active role in defining and implementing an enterprise integrated environment.) The information is listed under the categories of the organizations. The information on the various activities was obtained mainly from the following reports:

"Comparison of Other Integration Programs and Projects to the EIF" [DAC190] was the first attempt to report on on-going projects in EIF.

"Comparison of EIF Characteristics Versus Those of Other Known Integration Programs" [DAC290] prepared for the EIF project was an excellent source (when it was published) for the identification of both manufacturing and information technology programs that could support a coordinated EIF effort.

"Baseline Report on the Current State of U.S. Enterprise Integration Initiatives" [IDA91] prepared by IDA for the CALS program described projects that were working in EIF.

"Manufacturing and the NII: White Paper," prepared by NIST describes on-going efforts by industry and government that relate to enterprise integration [CATM94].

\section{A.1 GOVERNMENT ACTIVITIES}

\section{A.1.1 INTERAGENCY ACTIVITIES}

Information Infrastructure Task Force - A newly established inter-agency task force (led by NIST) that will work with Congress and the private sector to promote the policies and initiatives needed to accelerate deployment of a National Information Infrastructure [NII93].

Information Infrastructure Technology and Applications (IITA) Task Group - A newly established inter-agency task group (co-chaired by NSF and ARPA and under the overall High Performance Computing and Communications Initiative) that will coordinate the research and development efforts by the individual agencies to create the technology base 


underlying a universally accessible National Information Infrastructure (NII) and to use this technology to develop and demonstrate prototype "National Challenge" applications [IITA94]. (Among the challenges are Advanced Manufacturing and Electronic Commerce).

\section{A.1.2 AGENCY ACTIVITIES}

Air Force ManTech - Initiated (with the CALS Program) a joint EIF study in 1989 that was conducted by two industry teams (Northrop and IBM). The task was an effort to define and develop for national consensus a disciplined approach or framework that would promote U.S. industrial competitiveness through enterprise integration. The mission was to define a framework that would allow for the integration of the many programs, initiatives, and other activities, then suggest a method to gain national consensus for this framework (see [EIF90] and [EIFD89]). The Air Force has sponsored several programs related to EIF:

IISS - Build a large scale integrated information system. Implement the system based on the three schema architecture for databases.

PDDI - Develop a product definition data interface (served as the precluder to STEP).

IDS - Develop a data system to make engineering data available to field activities.

EIS - Develop a framework which addresses the problem of integrating CAD, CAM, CIM, and CAE tools.

EIP - Contribute to a national initiative for inter/intra-enterprise information system integration. Assist in a national consensus building; stimulate development of commercial products; and validate EI framework and guidelines as well as the core functional specifications and related standards.

ARPA - Has taken the lead in the development of many programs that involve both the technologies of concurrent engineering and enterprise integration.

DARPA Initiative in Concurrent Engineering (DICE) - Develop an architecture that can support concurrent engineering within an enterprise environment.

Manufacturing Automation Design Engineering (MADE) - Focus on the development and demonstration of key software elements for Integrated Product/Process Development (IPPD) and agile manufacturing applications for the NII. Thrust areas include (1) development of tools for conceptual design, (2) 
development and demonstration of tools for interoperability (this effort should result in new knowledge in areas such as design intent which should enhance standards such as STEP), and (3) demonstration of a scalable capability to share multiple types of distributed information among networked applications.

Agile Manufacturing Program - Develop a prototype of an information infrastructure to support distributed concurrent engineering, flexible manufacturing, and electronic commerce in manufacturing applications.

National Industrial Information Infrastructure Protocols (NIIP) - A new consortium, funded through the TRP, has proposed an innovative computer-based solution to enable widespread deployment of virtual enterprises within America's industrial community. It will incorporate the standards that government and industry have developed for object technology, product data, and computer communications to create a seamless environment for virtual enterprises. It will consolidate these standards into a cohesive solution that can be used and deployed broadly.

CALS - The Continuous Acquisition and Life-Cycle Support (CALS) Initiative is a DoDwide program to enable more effective generation, exchange, management, and use of digital data supporting the life cycle of a product through the use of international standards, business process change, and advanced technology application. The program has supported the development of such standards as IGES, SGML, ODA, CGM, and STEP (as well as FIPS for IDEF's). In the late 1980's CALS developed two main thrusts to the Multi-Enterprise Integration Framework effort that applied to U.S. Industry in general:

1. Investigate and characterize EIF, including:

a. Develop a tool set to assist in defining and implementing process improvements.

b. Partition the problem space, i.e., the number and role of the various disciplines and tasks which contribute to production.

c. Facilitate industry and professional society interest in implementing an integrated multi-enterprise environment.

2. Upgrade and expand international data standards for use in multi-enterprise integration.

At the present time, CALS has proposed, through a white paper, to extend the National Initiative for Product Data Exchange (NIPDE) to support a National Enterprise Integration Partnership (NEIP). CALS believes that the NEIP should address the integration of standards and technologies required in our technical platforms to meet today's complex 
business needs. CALS describes EI as enabled by business process reengineering and infusion of critical technologies. CALS lists many of the efforts that are described in this white paper (i.e., EDI, EC, HPCC) as being part of EI, but believes that the initial NEIP efforts should be in Electronic Commerce (EC) and Lean/Agile Manufacturing as the extension to Product Data Exchange. An important addition to the industrial players that are currently in the NIPDE Initiative is the CALS Industry Steering Group (ISG) which plays an integral part in the definition and implementation of Defense requirements. Key coordination players include US PRO (IPO), ANSI, and ISO for the standards area. CALS recommended that the CALS Shared Resource Centers, the NIST Manufacturing Technology Centers, and the Manufacturing Operations Centers could be used for technology transfer and education and training.

CALS believes that the NEIP coordination activity should be led by NIST. The activities include the joint working groups, supporting NIST laboratories, standards bodies, and technology transfer and education and training organizations. The joint working groups (consisting of industry and government participants) would demonstrate or test specific enterprise integration capabilities. The main products of the NEIP will be the results, findings, lessons learned, and benefits of the enterprise integration capability demonstrations.

DLA ManTech - Has taken a special interest in the development of the manufacturing framework and interface standards needed for apparel design and manufacturing.

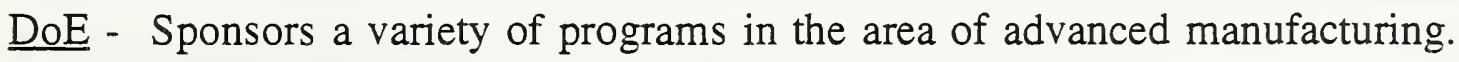

Technology Enabling Agile Manufacturing (TEAM) - Collaborate with industry to define critical technology needs and direct access to the resources that have created state-of-the-art manufacturing systems. Thrusts include Production Design and Enterprise Concurrency, Virtual Manufacturing, Manufacturing Planning and Control, Intelligent Closed-Loop Processing, and Integration.

Navy ManTech - Supported such efforts as the Automated Manufacturing Research Facility at NIST and the Rapid Acquisition and Manufacturing Program at SCRA. The Navy also led a Manufacturing Systems Committee of the DoD ManTech Advisory Group that developed a manufacturing systems strategic plan [MSSP92]. An important strategy in the plan was to invest in integration methodologies for the interoperation of new and existing information systems regardless of hardware vendor, software vendor, or physical location of the systems.

NIST - Supports the work in EIF in several ways. There is an intramural program aimed at research and development into the technology and standards needed for systems integration. As part of that program there has been an active partnership with the CALS 
program to jointly work to ensure that the necessary information technology standards needed for CALS are developed with effective conformance testing activities. In addition there are two extramural programs, the Advanced Technology Program and the Manufacturing Extension Partnership, that sponsor efforts by industry to make U.S. manufacturing more competitive.

Intramural programs include such efforts as the National PDES Testbed and the newly created Systems Integration for Manufacturing Applications project.

National PDES Testbed - A jointly sponsored effort by NIST and DoD/CALS to facilitate the development and implementation of STEP through the creation of the necessary methodologies, tools, and testing capabilities.

Systems Integration for Manufacturing Applications (SIMA) - A new effort by NIST that addresses the development of a fully integrated set of manufacturing systems using High Performance Computing and Communications (HPCC) technology. Its primary focus is on concurrent product and process design and integrated production planning and control. In addition SIMA includes a standards-based data exchange effort for CIM that will focus on the improvement of data exchange among computer aided design, process, and manufacturing activities. Applications may include enterprise integration for manufacturing applications, integrated product/process design, simulation and agile manufacturing.

Office of Enterprise Integration - A newly formed function that provides a focal point for efforts throughout NIST laboratories that develop technical underpinnings for applications of information technology in areas such as manufacturing, construction, health care, and government services. This office will also provide an initial point of contact for policy makers and researchers in industry, academia, and government interested in learning more about NIST activities in related areas such as CALS and electronic commerce.

The ATP sponsors the development of advanced technology that has a demonstrable path to commercialization. Two key projects funded have been Rapid Response Manufacturing (see NCMS) and PreAmp (see PDES, Inc.). At the present time, there have been several public workshops to identify new programs in the area of Open CIM Frameworks and Virtual Enterprises. If either of these programs become focused funded efforts (the former has been funded as the CIM for Electronics Program), they would have a strong impact on the EIF developments.

The MEP sponsors the transfer of manufacturing technologies to mid- to small-size companies by working through the Manufacturing Technology Centers and other types 
of outreach programs.

Manufacturing Extension Partnership (MEP) LINKS - Establish a program called Technologies for Effective Cooperation Network (TECNet) that demonstrates linkages among the Manufacturing Technology Centers.

Manufacturing Extension Partnership Electronic Network (MEPNet) - Expand and enhance the TECNet by employing the capabilities of the EInet (from MCC).

\section{A.2 JOINT INDUSTRY/GOVERNMENT ACTIVITIES}

National Initiative for Product Data Exchange (NIPDE) - Coordinate the development and deployment of product data exchange standards. Consists of combination of industrial and government organizations. Key to its functioning successfully is an Executive Board of high-level government officials and vice presidents of major corporations.

\section{A.3 INDUSTRIAL CONSORTIA ACTIVITIES}

Agile Manufacturing Enterprise Forum - A collection of companies that has developed a competitive strategy for U.S. business based on the trends of total quality management and decentralization. The strategy is heavily dependent on the use of communications and information technologies to extend the boundaries of a business enterprise to a global scale. The implementation plans reference the use of standards. There are several subcommittees within the forum that look at issues such as enterprise integration and standards. A key objective of the forum is to contribute to the creation of a national manufacturing information network that will facilitate electronic commerce and the routine formation of virtual companies. The forum has developed the concept of the AgileNet as the realization of a Factory America Network. The core components of the network consist of MCC's EI Net, NCMSs on-line version of its Manufacturing Information Resources Center and its Teaching Factories network. In FY 94, the forum has created four new groups, of which the Agile/Virtual Enterprise group is key to Enterprise Integration methodologies.

In a new report "21st Century Manufacturing Enterprise Strategy - Integrating the Agile Virtual Enterprise (Key Need Areas) Volume 3" [AMEF93], the importance of adaptable standards was emphasized. Standard - cultural, business, and technical - must respond to changes such as technology advancements and/or business practices, to enable the enterprise to deliver the highest quality product at the lowest cost within the schedule. Several key need areas were specified with many references to standards:

Concurrency (organizing core competencies of enterprise in a manner that reduces product realization time) - The development of product data exchange standards 
and their implementation are critical to concurrency. These standards (e.g., PDES/STEP) include much more than product geometry. Environmental models and characterization, functional properties, assembly sequences and tolerances, and many more attributes - including business data - must be shared in mutually usable databases.

Synchronized processes ( coordination of product life cycle processes) - The establishment of standards for Product/Process Integration (e.g. STEP/PDES) for exchanging information requires developing an information model that represents the information needs of the enterprise.

Information System Infrastructure (Develops around and supports the enterprise's ability to implement and use (re)configurable processes and products) Information system standards are of paramount importance to the information system infrastructure of the enterprise. This requires standards for data, communications, support applications, technical applications, and user interfaces.

Rapid Response (an enterprise's ability to rapidly reconfigure processes and products to meet the unanticipated demands of the customer) - Standardized interfaces are an imperative for rapid response.

Adaptive Infrastructure (supports the enterprise's quest for agility by enabling new processes to be integrated into the existing processes) - This must support the access of distributed information sources. Tools are necessary to solve interoperability and performance problems.

AMICE - This is an European CIM architecture consortium that is funded under the ESPRIT program. Their program has led the way to identifying the technology and standards for EIF known as CIM-OSA [IJCI90]. The objectives of the program were: (1) develop an open-systems architecture for CIM systems, called CIM-OSA, (2) address the needs of industry, (3) support the development and implementation and operation of CIM systems, (4) support multi-vendor system environments with new and/or existing components, (5) influence standardization activities, and (6) increase the level of product stability from the user's point of view. The basic concept of CIM-OSA was to create a modelling framework and then derive particular implementation models of enterprises. CIM-OSA is known by its "cube" which gives a three dimensional view of the enterprise. The first view is by stepwise generation with 4 view elements: function, information, resource and organization. The second view is by stepwise instantiation with three elements: generic building blocks (or primitive), partial models (or industrial), and particular models (or company). The third view is by stepwise derivation with 3 elements: requirements definition, design specification, and implementation description. 
Lean CIM-OSA - This is phase three of the CIM-OSA project. The work is expected to find its way into the international standardization arena through the national standards bodies within the European countries.

The following is a new press release issues by AMICE through Kurt Kosanke, the project manager. The release was entitled "ONE MORE STEP TOWARDS ENTERPRISE INTEGRATION - Model Driven Shop Floor Operation Control and Monitoring based on CIM-OSA - Open Systems Architecture for CIM":

"RWTH Aachen, February, 1994: Integration in manufacturing becomes a reality at the shop floor of the Aachen Teaching Factory. Driven by a model of the order process for small batch size production, mechanical parts are produced according to priorities of incoming orders and the current capabilities of the shop floor. The CIM-OSA-based model is engineered for ease of use providing high flexibility in order execution.

The ESPRIT Project AMICE presented its final results on CIM-OSA in an open workshop held at the Teaching Factory (ADITEC) in Aachen, describing the use of the AMICE Project in enterprise engineering and enterprise operation control and monitoring. CIM-OSA implementations at FIAT and WZL were presented and demonstrated. Pre-product versions of modelling tool developments were also presented by several Consortium members.

CIM-OSA was used to optimize a FIAT gearbox production and assembly operation including both material and logistics flow. Different production strategies were simulated in the same model showing the benefits of a mixed push-pull production strategy compared with a pure Kanban implementation. CIM-OSA demonstrated excellent business benefits compared with other state of the art business modelling approaches. These benefits were quantified in significant reduction in the time to model these strategies and simulate their effects of the business.

WZL used CIM-OSA to model and simulate the complete order cycle for small batch size product families. This included order entry, product planning, production, distribution, and invoicing. Again, CIM-OSA demonstrated its abilities to test out different solutions and its flexibility to handle different application areas like business process re-engineering, lean organization, total quality management, and control.

CIM-OSA has been used at WZL also for model-driven shop floor operation control and monitoring. The CIM-OSA Integrated Infrastructure (IIS) enabled business process control in a heterogeneous IT environment. The IIS 
implementation used OSF/DCE (Open System Foundation/Distributed Computing Environment) as a common platform on hardware and software from different IT vendors, including Hewlett Packard, IBM, and Siemens Nixdorf. The integration of order processing, MRP-II based production planning, shop floor production planning refinement and manufacturing process control and monitoring was the major part of the demonstration. The order flow between the different operation steps was shown in a presentation via large screen projection. Following this presentation, the order was actually executed on the shop floor. This involved manufacturing the parts with milling, drilling, turning processes as well as the use of automated guided vehicles for transportation between process stations.

The CIM-OSA specification will be maintained in the future by the CIM-OSA Association: a newly formed group that was announced at the Aachen Workshop. Founding members of this group are industry and research organizations from ESPRIT Consortium AMICE. The CIM-OSA Association will engage itself in the controlled evolution of the CIM-OSA specification and information dissemination to the general public and to national, European, and international standards bodies. Application for membership is encouraged for any organization involved or interested in CIM-OSA."

American Textile Partnership (AMTEX) - Develop a computer-based communications, analysis, and simulation architecture to link the entire textile supply chain to an electronic marketplace. This effort is a combination of industrial consortium with DoE laboratories.

CAD Framework Initiative (CFI) - Develop worldwide industry guidelines for electronic design automation tools and their supporting environments that will remove barriers to integration.

CALS/CE Industry Steering Group - An industry volunteer group that works closely with the CALS program to facilitate the development and implementation of the information standards defined by CALS. Several study groups, including the Concurrent Engineering Framework Group, the Standards Group, the Data Dictionary Group, and the CITIS Technical Advisory Group have been created and have been developing key position papers on the relevant technologies and standards.

The ISG has created a CALS vision : Economic Growth Through Worldwide Enterprise Integration. The following is the vision as published by NSIA:

"The goal of the CALS Initiative is to enable integration of enterprises on a worldwide basis. The vision is for all or parts of a single enterprise, or for example, an original equipment manufacturer and its suppliers, or a consortium of public and private groups and academia, to be able to work from a common 
digital database, in real time, on the design, development, manufacturing, distribution and servicing of products. The direct benefits would come through substantial reductions in product-to-market time and costs, along with significant enhancements in quality and performance.

In order to create this networking capability there needs to be developments in both technology and in working practices. An "electronic highway", or network, is an essential segment of this information infrastructure. Basic tenets of the CALS initiative assume an open systems environment, the early adoption of emerging commercial standards and international coordination on standards for data exchange."

CALS began as primarily a US defense industry and government effort to integrate systems development, production and support, but has become recognized as a leading edge prototype for a manufacturing community "virtual enterprise" in the 21 st Century. As such, CALS has been accepted as the focus for enterprise integration in nations throughout Europe and the Pacific Rim.

Center for Electronic Commerce - managed by ITI and provides a bridge between government and industry for electronic commerce.

Consortium for Advanced Manufacturing - International (CAM-I) - Sponsors the Computer Integrated Enterprise (CIE) that has completed a framework for CIM that incorporated some of the CIM-OSA work along with much of its own original work. For over six years, the CIE has been recognized for its research in systems integration architectures/frameworks, benchmarking of world-class manufacturing organizations and development of an industrial consensus on guidelines and methodologies for Enterprise Integration.

In a letter to me dated March 31, 1994, Bob Boykin described a new focus on "The Next Generation Enterprise." The research will build upon several national and international efforts including Fraunhofer's "Fractal Factory" Concept, Japan's Biological Manufacturing Systems and Autonomous Distributed Manufacturing Systems (ADMS) research, the U.S. Agile Enterprise Vision, the NIST Systems Integration for Manufacturing Applications (SIMA), and the CAM-I's Next Generation Manufacturing Systems (NGMS) program. A key issue will be defining an industrial consensus of understanding of features and attributes of the new era of competitive manufacturing systems integration. Within the Next Generation Enterprise, the relevance and magnitude of PDE is clear. It is believed that CAM-I's U.S. manufacturing corporate members will explore this critical attribute extensively. 
CORBA - This is an object oriented approach to integration of enterprise information and systems based on a concept of high level information technology (IT) services (similar to CIM-OSA integrating infrastructure). It is based on the work of the Object Management Group and IT industry consortium that is developing informal standards for Object Oriented environments.

IDEF Users Group - Has taken ownership of the IDEF modeling methodologies. They are directing efforts towards extending the existing methodologies to include the modeling of enterprises. The IEEE serves as the standards sponsor for the IDEF effort. The formal definition of the IDEF is "A structured analysis and design method for graphical and textual descriptions of activities, activity relationships, information, and information relationships used to develop enterprise and system level architectures."

For example, there is a conference "Re-inventing the Enterprise ... Technologies of Change" being held in May 1994 to express the uniqueness of IDEF in addressing the full life cycle of tasks needed to both conduct analysis and execute improvements.

Microelectronics and Computer Technology Corporation (MCC) - This consortium has an enterprise integration division which sponsored (under Air Force funding) the International Conference on Enterprise Integration Modeling Technology [ICEI92]. The program is investigating the complex issues surrounding enterprise integration and have proposed technical solutions such as the EI Net.

National Center for Manufacturing Sciences (NCMS) - Developed jointly with the NIST/ATP the Rapid Response Manufacturing program which intends to enhance and adopt key technologies to enable use of advanced, highly integrated systems for manufacturing. In addition to the technical programs, NCMS, through its computer integrated operations, supports the development and information integration efforts for manufacturing. For example, sponsors work in Next Generation Controller, MAP, and Manufacturing Message Specification (MMS).

National Computer Graphics Association (NCGA) - Serves as the administrator for the US PRO. Has run the Roadmap 2000 demonstration.

National Security Industrial Association (NSIA) - Serves as the administrator for the CALS ISG and for CALS EXPO.

PDES, Inc. - A consortium of over twenty major manufacturing and CAD vendors whose purpose is to accelerate the development and implementation of STEP. Some of the key programs include: (1) AEROSTEP - Show viability of STEP AP 203 (Configuration Controlled Design) as an exchange mechanism supporting Digital Pre-Assembly of 
engine/strut interface, (2) Advanced Weapon System Pilot - A joint initiative with DoD to demonstrate AP 203 and AP 202 (Associative Draughting) in an Advance Weapon System design to manufacture usage scenario, (3) develop AP 207 (Sheet Metal Die Planning and Design), and (4) PreAmp - a joint effort with the NIST/ATP to develop applications in electronic wiring assembly.

Roadmap 2000 - This is a coalition of more than 30 government, public and private organizations that have joined forces to examine the life cycle processes as promoted by the CALS technology. There have been demonstrations of the existing computer systems at the last two CALS EXPOs. A permanent site is being explored for the demonstration. Martin Marietta has taken over from NCGA as the EXPO coordinator for the demonstration.

Sematech - A consortia of semiconductor equipment manufacturers, end-users, and software vendors that has developed many programs in the area of EIF:

SCC - Develop maintainable and changeable semiconductor cell controllers. Reveal voids in the current global base of application standards and develop new standards.

Open CIM Framework - A new effort by Sematech to define a CIM architecture that handles semiconductor manufacturing applications.

Smart Valley, Inc. - Developed CommerceNet which provides an open, internet-based infrastructure to support exchange of electronic data (run by consortium of Silicon Valley electronic manufacturers, software developers and information service providers).

Society of Manufacturing Engineers (SME) - Works on a variety of projects to promote CIM. A key project that was sponsored was ENE $88 \mathrm{i}$ which showed users that the time had come to implement MAP/OSI networking and give vendors a vehicle by which they could present and promote their products. 


\section{APPENDIX B}

\section{STANDARDS DEVELOPMENT PROGRAMS}

From a standards perspective, the U.S. TAG to TC184 (the ISO technical committee responsible for Industrial Automation Systems) has taken the European document and modeled a U.S. strategy using the same format. The draft document entitled "U.S. TAG to ISO TC 184 Program of Work Working Draft 1.0" [TAG89] was circulated among TAG members for comments. It replaced the sections identifying "current work" with "current U.S. work", "current ISO/IEC work", and "external work". The report identified significant gaps in U.S. standards activities that are critical to the development of Advanced Manufacturing Technology. However, no work has been done on this document since it was originally issued. The EIF concept is needed to better identify the spectrum of standards and technologies and provide a mechanism for determining the criticality of standards efforts.

The following is the list of the key standards (or specifications) organizations that have some involvement in an aspect of EIF:

American Apparel Manufacturers Association (AAMA) - Under ANSI, it develops standards that facilitate the manufacturing communication in apparel operations. For example, AAMA is developing a neutral format for exchanging pattern data between $\mathrm{CAD}$ systems.

American National Standards Institute (ANSI) - Among its many functions are to support the development of information technology-related standards and computer integrated manufacturing-related standards. For example, it supports work in X3 (see CBEMA) and $\mathrm{X} 12$ (see DISA) related to communications and data management. The IPO is also under ANSI. Recently ANSI was awarded a Technology Reinvestment Program (sponsored by ARPA) called "National Standards Systems Network (NSSN)" The goal of the project is to develop a NSSN electronically linking thousands of small, medium, and large U.S. companies, private and government organizations, and educational institutions involved in production, delivery, and use of over 100,000 U.S. government and private sector standards.

American Society for Mechanical Engineers (ASME) - Under ANSI, it develops standards in the area of Dimensional Metrology (B89) and Drawings and Drafting Practice (Y14).

American Society for Testing and Materials (ASTM) - There are a large range of standards activities that relate to guidelines for designing, rapid prototyping, documenting, 
and procuring CIM systems.

Automotive Industry Action Group (AIAG) - Improve productivity in the automotive industry by reaching consensus solutions to common business needs. Many standards have been generated that involve exchange of information between companies. (Works closely with ANSI X12 (EDI) and IGES.)

CAM-I - In addition to developing technical programs in the area of CIM and EIF, CAMI is an accreditated standards body with a scope that includes a broad range of CIM related activities. The official scope is "information preparation for CIM systems and methods related to standard software input/output, interfaces and language specifications." CAM-I has for over twenty years been actively involved in representing their manufacturing industry members on national and international standards bodies. Several CAM-I programs participate in these activities including CAM-I/IMAR Dimensional Inspection Techniques Specification (DITS) and CIE in Enterprise Integration efforts.

In a letter to me from Bob Boykin, he made the following statements: "CAM-I and its industrial membership strongly supports the industrial and federal efforts in PDE by the U.S. IPO and PRO. Close coordination and cooperation between CAM-I programs (including CIE, NGMS, and QC/QS); U.S. IPO and U.S. PRO is viewed as of national importance and reciprocally beneficial. I look forward to strengthening our relationship."

CEN/CENELEC - The European equivalent to the ISO and IEC international activities. The key activity concerned with EIF is ITGEM (WGARCH) which is charged with the development of a draft standard for a set of services that make up an integrating infrastructure that would support a CIM-OSA environment. For example there is a document "ENV 40003-90 - Information Processing in Automation - Computer Integrated Manufacturing - CIM System Architecture Framework for Modeling" that is being considered as an European standard.

CIM Standards Board - One of eleven coordinating boards within ANSI. The Computer Integrated Manufacturing Standards Board (CIMSB) is authorized by ANSI to coordinate the industrial automation standards activities in the United States. The scope of the board is to "Develop policies relative to CIM which represent harmonized and coordinated recommendations on national and international standards. These positions will result from an open exchange with all organizations operating in the Computer-Aided Engineering, Computer-Aided Design, Computer-Aided Manufacturing, Computer-Aided Test, and related standardization areas." The CIMSB needs to initiate a national strategic plan of its own. At the present time, it is using the standards taxonomy from the AMT report [ITAE90] to determine how to classify and coordinate the relevant standards activities. 
Computer and Business Equipment Management Association (CBEMA) - Secretariat for the ANSI standards "X3 - Information Processing Systems." The scope is in the area of computers and information processing and peripheral equipment, devices and media related thereto. Some example standards are described below:

Information Resource Dictionary System (IRDS) - Intended to provide builders and users of enterprise integration information frameworks facilities to create, maintain, and access an Information Resource Dictionary (IRD) and the associated IRD definitions (sponsored by JTC1 SC21/WG3 and X3H4).

Open Distributed Processing (ODP) - Its intent is to produce a reference model for distributed processing (sponsored by X3T3, ODP Consortium, and ANSA - an European consortium).

Remote Data Access (RDA) - An effort to develop a standards protocol for communication for a distributed database system (sponsored by X3H2.1)

Standard Query Language (SQL) - Intended to provide a standard query language for database management systems (sponsored by $\mathrm{X} 3 \mathrm{H} 2$ ).

Corporation of Open Systems (COS) - Supports and promotes open systems based technologies for communications. For example, organized the MAP/TOP users group and the Users Alliance for Open Systems.

Data Interchange Standards Association. Inc. (DISA) - Serves as the secretariat for X12 which is part of ANSI. This committee develops uniform standards for electronic interchange of business transactions. The standard is commonly referred to as Electronic Data Interchange (EDI).

Electronic Industries Association (EIA) - Serves in a broad spectrum of electronics standards, but the relevant standards to EIF include EDIF (Electronic Data Interchange Format) and IEC/TC93 (for which it is the secretariat) which is concerned with design automation which parallels ISO/TC184/SC4. The official scope is: "Standardization to enable the integration and automation of electrotechnical product design, engineering, manufacturing, and logistics support processes, and to facilitate procedures for product operation and maintenance. This standardization should also support the integrated system design of electrotechnical products which encompasses the electrical, electronic, electromechanical and embedded software performance aspects."

IFIP/IFAC - An international group that looks at key information processing and automation control technologies. A new task force, Architecture for Integrating Manufacturing Activities and Enterprises, has been set up for defining and evaluating 
enterprise reference architectures. There are detailed studies of CIM-OSA, GIM and the Purdue enterprise reference architectures (see [IFAC93] and DIIS93]).

IGES/PDES Organization (IPO) - This is a standards body under the US PRO with the responsibility for developing standards in the area of product data exchange. At the present time the two key standards are IGES and STEP (as defined nationally under the PDES project).

Initial Graphics Exchange Specification (IGES) - Sponsored by the IPO, it defines a neutral file format for transferring data used to represent the geometric information about a product. These data are typically contained in and generated by a CAD program.

Product Data Exchange Using STEP (PDES) - The U.S. effort in support of the international effort STEP.

The present scope for the IPO is the following:

"The IGES/PDES Organization exists to develop and gain consensus approval of standards and specifications for the exchange and sharing of digital product data. Product data includes relevant information that spans the entire life cycle of a product. The life cycle of a product ranges from product concept to design to manufacturing to logistic support of the product and its users. The standards required to exchange product data include data models and modeling methods, databases, and methods for user and software access to the product information.

Digital product data results from the application of many existing disciplines, practices and standards. Use of digital product data is frequently through application tools that may adhere to one or more existing standards. Access to unambiguous product data through application tools requires that the product data exchange and sharing standards include all of the meaning and relationships needed by the application tools and other applicable standards. The work of existing standards bodies will be recognized and supported as they relate to the work of the IGES/PDES Organization.

Development of electrical and electronic standards shall be done in a manner consistent with and in support of existing and planned national and international standards specifying electrical and electronics products. In particular, the IPO efforts will be consistent with and complementary to the work of the IEEE Computer Society Design Automation Standards Subcommittee (DASS) and to other IEEE and EIA standards in the area of electrical schematics and graphics." 
Information Systems Standards Board (ISSB) - One of the eleven coordinating boards within ANSI. The ISSB is authorized by ANSI to coordinate the information systems standards activities in the United States.

Institute of Electrical and Electronics Engineers (IEEE) - Supports the development of information technology related standards. For example - local area networks (802), operating systems (POSIX), and software engineering. The standards associated with IDEF are all included within this body. In addition, the work on VHDL, the design language for VISIC, is part of the IEEE efforts.

Instrument Society of America (ISA) - Deals with a broad spectrum of instrumentation technology. Of specific interest to EIF is the work in data highways such as PROWAYLAN for an industrial data highway and Field Bus for industrial control systems.

International Electrotechnical Commission (IEC) - This organization functions at the same level as ISO, but limits its scope to the electronics and electrical areas. Besides the TC93, there is TC44 (Electrical Equipment of Industrial Machines) which prepares standards for interfaces between control equipment, and TC65 (Industrial Process Measurement and Control) which prepares standards for systems and elements used for industrial-process measurement or control concerning continuous batch processing.

International Organization of Standardization (ISO) - Supports a variety of international standards activities. The key efforts of interest to EIF fall within the TC184 (Industrial Automation technical committee).

JTC1 - A joint international standards effort between ISO and CCITT to develop information technology standards. It is the counterpart to the ANSI X. national effort. Some of the relevant subcommittees are: SC6 (Telecommunications and Information Exchange Between Systems), SC7 (Software Engineering), SC14 (Data Element Principles), SC21 (Information Retrieval, Transfer and Management for Open Systems Interconnection), SC22 (Programming Languages - Their Environments and Systems Software Interfaces), SC24 (Computer Graphics and Image Processing), and SC27 (IT Security Issues).

National Electrical Manufacturers Association (NEMA) - Serves as the secretariat for ISO/TC184/SC5 and the CIMSB.

NIST - Although not an official standards body, NIST is involved in the management of many of the key standards activities.

IPO - NIST serves as the chair. 
ISO/TC184/SC4 - NIST serves as the chair and secretariat.

Application Portability Profile (APP) - Provides guidance to assist Federal agencies in making choices regarding the selection and use of Open System Environments, and in the development of application protocols based on the APP. (It is not really a standard.)

Federal Information Processing Standards Publications (FIPS PUBS) - An effort by NIST to develop publications for U.S. agency wide standards for computer software, hardware, data management, networks, and security.

ODP Consortium - Develop an adequate testing infrastructure to ensure acceptance of the ODP standard whose intent is to produce a reference model for distributed processing. (This is sponsored by X3T3, ODP Consortium, and ANSA - an European consortium).

TC184 - The ISO technical committee that sponsors all the work in industrial automation (NEMA is the Administrator). There are four subcommittees, two of which are SC1 (Physical Device Control) and SC2 (Robots for Manufacturing Environment). The other two are described below.

TC184/SC4 - Sponsors work in global manufacturing, languages and industrial data. There are several key areas within the subcommittee:

WG2 - Sponsors the work in CAD libraries.

WG3 through WG7 - Sponsors the Standard for the Exchange of Product Model Data (STEP) which is an effort to develop a neutral representation of the product data necessary to describe a product across its life-cycle.

WG8 - Sponsors the work in manufacturing data exchange (e.g., factory status, process plans), commonly referred to as MANDATE.

WG9 - Sponsors efforts to harmonize the product data exchange standards for electronic products.

TC184/SC5 - Sponsors work in manufacturing architecture and communications. There are several key areas within the subcommittee:

WG1 (Known as Modeling and Architecture) - Develops the enterprise integration framework and enterprise modeling standards. At present has a working draft for Framework for Enterprise Modeling which provides a modeling based platform for the integration of enterprise information and the creation of applications that 
support the execution of business processes.

WG2 - Develops the factory communication standards such as MAP and MMS.

WG4 - Developing Manufacturing Application Programming Language and Environment (MAPLE). This effort is a focused subset of the concept of having an integrating infrastructure of high level IT services that enable a business to integrate their IT and manufacturing systems by supporting a flexible programming environment.

$\underline{X / O p e n}$ - Develop and promote open systems technologies. Published portability guides for transport, object management and X.400 protocols.

\section{B.1 MAJOR STANDARDS FOR ENTERPRISE INTEGRATION}

There are a collection of enterprise integration related standards that need to be closely coordinated. Randy Aranguren, convener of TC184/SC5/WG1, developed a set of standards profiles showing the EI trends for the periods: current, 2 to 7 years, and 8 years $\&$ beyond. The tables include the types of services defined under enterprise integration activities, the primary standards being used to satisfy these activities, and the secondary standards that have not yet reached prominence (or are being phased out) for these same activities.

Enterprise Integration focuses today on the use of specific languages and interfaces to facilitate data sharing and interoperability within a business.

TABLE B.1 CURRENT MAJOR STANDARDS

\begin{tabular}{||l|l|l||}
\hline \hline SERVICES & PRIMARY STDS & SECONDARY STDS \\
\hline \hline OPERATING SYSTEMS & UNIX, OSF/DCE & SAA, NEWWAVE, NAS \\
\hline USER INTERFACE & MOTIF, X-WINDOW & OPEN LOOK \\
\hline PROGRAM & $\begin{array}{l}\text { C, COBOL, FORTRAN, } \\
\text { ADA }\end{array}$ & $\begin{array}{l}\text { CASE, COHESION, } \\
\text { AD/CYCLE }\end{array}$ \\
\hline DATA MANAGEMENT & SQL, FTAM & RELATIONAL SQL \\
\hline DATA EXCHANGE & ODA/ODIF, EDI, IGES & OSI, CGI/CGM \\
\hline GRAPHICS & IGES, PHIGS & OSI, CGI/CGM \\
\hline NETWORK & $\begin{array}{l}\text { ETHERNET, TCP/IP, } \\
\text { NOVELL }\end{array}$ & MMS, OSI(GOSIP) \\
\hline
\end{tabular}

In 2-7 years, state of the art in enterprise integration will achieve interoperability and begin to realize limited portability through neutral interfaces. The focus will be on networks that extend beyond the boundaries of a single business. 
TABLE B.2 MAJOR STANDARDS 2-7 YEARS

\begin{tabular}{||l|l|l||}
\hline \hline SERVICES & PRIMARY STDS & SECONDARY STDS \\
\hline \hline OPERATING SYSTEMS & POSIX, X-OPEN & OSF SRVCS \\
\hline USER INTERFACE & MOTIF, X-WINDOW & VT(OSI) \\
\hline PROGRAM & $\begin{array}{l}\text { C, COBOL, FORTRAN, } \\
\text { C++ }\end{array}$ & $\begin{array}{l}\text { ADA, PCTE, JTC1SC7, } \\
\text { OMG(CORBA) }\end{array}$ \\
\hline DATA MANAGEMENT & SQL, FTAM, OSF/DCE & STEP, IRDS, OOSQL \\
\hline DATA EXCHANGE & $\begin{array}{l}\text { ODA/ODIF, EDI, } \\
\text { EIA/CDIF, STEP }\end{array}$ & $\begin{array}{l}\text { OSI, CGM(ISO), IGES, } \\
\text { HYTIME }\end{array}$ \\
\hline GRAPHICS & PHIGS/PEX, CGM, IGES & POSTSCRIPT(OSI) \\
\hline NETWORK & OSF/DCE, OSI X, MMS & TP(ISO), GOSIP \\
\hline
\end{tabular}

In the period 8 years and beyond, enterprise integration will eventually reach full portability across heterogeneous systems. EI applications such as communications, data transfer, distributed execution, etc. will all become seamless to the user due to semantic unification and standardized infrastructure components.

\section{TABLE B.3 MAJOR STANDARDS 8 YEARS AND BEYOND}

\begin{tabular}{||l|l|l||}
\hline \hline SERVICES & PRIMARY STDS & SECONDARY STDS \\
\hline \hline OPERATING SYSTEMS & POSIX, OSF/ODP & TC184/SC5/WG1 - (IIS) \\
\hline USER INTERFACE & API STDS W/TOOLS & TC184/SC5/WG1 \\
\hline PROGRAM & $\begin{array}{l}\text { PCTE+CASE, } \\
\text { OMG(CORBA) }\end{array}$ & $\begin{array}{l}\text { STEP, } \\
\text { TC184/SC5/WG4(MAPLE) }\end{array}$ \\
\hline DATA MANAGEMENT & OOSQL, IRDS, FTAM & OMG(CORBA), STEP \\
\hline DATA EXCHANGE & STEP & $\begin{array}{l}\text { EIA/CDIF, EDIFACT, } \\
\text { OMG(CORBA) }\end{array}$ \\
\hline GRAPHICS & PHIGS/PEX & CGI/CGM, IGES \\
\hline NETWORK & $\begin{array}{l}\text { CMIS/CMIP (DCE/DME- } \\
\text { TP4) }\end{array}$ & MMS, OSI(GOSIP) \\
\hline
\end{tabular}

\section{B.2 MAJOR STANDARDS FOR CALS}

The CALS Industry Steering Group has a strong interest in the development of standards for enterprise integration. The Requirements and Technology Assessments Division maintains a listing of key standards for CALS which are summarized below: 
TABLE B.3 LIST OF MAJOR CALS STANDARDS

\begin{tabular}{|c|c|}
\hline TYPE & IDENTIFICATION \\
\hline DATA - PRODUCT DATA & ISO/DIS 10303(STEP), USPRO/IPO-200 \\
\hline DATA - BUSINESS DATA & X12(EDI), UN-EDIFACT \\
\hline $\begin{array}{l}\text { INFORMATION PROCESSING - } \\
\text { INFORMATION ENGINEERING STDS }\end{array}$ & IDEF0, IDEF1X, EXPRESS \\
\hline $\begin{array}{l}\text { INFORMATION PROCESSING - DATA } \\
\text { BASE STANDARDS }\end{array}$ & $\begin{array}{l}\text { IRDS, IRDS II, SQL, SQL/3, SQL/ERI, } \\
\text { SQL/MM, RDA }\end{array}$ \\
\hline $\begin{array}{l}\text { INFORMATION PROCESSING - TEXT } \\
\text { STANDARDS AND TOOLS }\end{array}$ & $\begin{array}{l}\text { SGML(ISO8879), SGML(MIL-M-28001), } \\
\text { MIL-HDBK-SGML }\end{array}$ \\
\hline $\begin{array}{l}\text { INFORMATION PROCESSING - } \\
\text { GRAPHICS STDS AND TOOLS }\end{array}$ & $\begin{array}{l}\text { IGES, IGES(MIL-D-28000), } \\
\text { RASTER(MIL-R-28002), CGM(MIL-D- } \\
\text { 28003) }\end{array}$ \\
\hline $\begin{array}{l}\text { INFORMATION PROCESSING - CALS } \\
\text { DATA INTERCHANGE }\end{array}$ & $\begin{array}{l}\text { MIL-STD-1840, MIL-STD974(CITIS),MIL- } \\
\text { HDBK(59),MIL-T-31000 }\end{array}$ \\
\hline $\begin{array}{l}\text { INFORMATION PROCESSING - } \\
\text { NETWORKING STANDARDS }\end{array}$ & $\begin{array}{l}\text { X.435(EDI MESSAGING), } \\
\text { X.500(DIRECTORY) }\end{array}$ \\
\hline $\begin{array}{l}\text { INFORMATION PROCESSING - } \\
\text { SECURITY STANDARDS }\end{array}$ & $\begin{array}{l}\text { OPERATING SYSTEM, DATABASE, } \\
\text { NETWORK, USER }\end{array}$ \\
\hline
\end{tabular}


